\title{
Computerized Power Montoring System for EEDC Umuahia
}

\author{
*Ugwoke, F. N. \\ Computer Science Department, Michael Okpara University of Agriculture, Umudike, Abia State, Nigeria.
}

\begin{abstract}
The computerized process in any facet of human existence or any sector of any economy promotes efficiency accuracy, effectiveness, improved service delivery and many more. This is also applies to the computerization of power monitoring processes. Computer aided monitoring devices eliminated errors due to human limitations, preserve data effectively and alleviate complaints emanating from aggrieved customers. In view of this, the study proposes a prototype of a computerized power monitoring system, as explores its associated benefits and technicalities. An indepth literature review is provided to establish a proper foundation for the appreciation of subject matter. In conclusion, the study upholds the fact that the full automation of processes in the power sector is the best for our economy, as it calls for the development of computer experts in the sector.
\end{abstract}

Keywords: Computerized process, data, EEDC and Umuahia.

\section{Introduction}

The use of computer (information technology) in electric power monitoring and control is vastly gaining organization acceptance. The monitoring system starts from data collection (meter reading). Monitoring or inspection carried out to get meter reading from customers" homes, transformer status at various locations, to fault detection, such as electric cable condition and soon. These monitoring processes are either manual or partially automated, and as such associated with errors which cause inaccuracy and unreliability. The computer aided monitoring devices eliminate errors due to human limitations, preserve data effectively and alleviate complaints from aggrieved customers.

There is a glaring need for the utilization of information Technology (IT) and computing potential in revolutionizing the nation's mode of power management and principals. This will serve as a vehicle for the drive toward a fully automated or computerized power monitoring processes. It will also provide the needed solution to most of the challenges resulting from the existing system which is potentially computerized.

In this study, the design of a computerized power monitoring system is offered to foster the drive toward the full computerization or automation of the processes in the power sector. Chapter two of the study present an in-depth literature review of relates publication. The methodology or system analysis and design of the proposed system is describe in chapter three, chapter four contain the program design and documentation, while the conclusion, summary, and recommendations are proposed in chapter five of the study.

The distribution of electricity is characterized by inadequate funding, poor billing and data collection efficiency, poor theft, high equipment vandalization, inadequate and ineffective customers' management relationship and practice, etc.

On the part of EEDC it has been a tedious task to keep at breast with up to date facilities, electricity cables, transformers, etc. these inabilities contribute to their poor and attention to critical power problems.

As a matter of necessity, only an online, real time monitoring transaction processing system can revert these plagues associated with manual procedures of power monitoring system. The question of turning to the computerized system rather than partially automated system which results in some form of discomfort due to poor operating environment becomes a major issues to be resolved. When the concept/issue of computing arrives, people develop some reluctance or hesitation; but with time, the need to keep an open door to the information age comes knocking Jacobson (2010) indicated that today's electric power generating plants are so large and complex that manual operation combined with analog sub-up control has become costly and undependable. He added that although the choice of proper equipment is important for any data handling and control system equipments done manually are inadequate in ensuring completely satisfactory operations. $\mathrm{He}$ proposed the RW.300 control and monitoring system with the following specifications:

- Typical Installation: A typical RW.300 control and monitoring system for generating plants includes an RW.300 Digital control computer as the central unit; analog and digital input and output equipment; standard measuring and sending instruments for pressure, temperature, floors and so on; indicating control devices activated by the computer.

- Logging of Data: under the control of the logging program, a large number of input quantities are 
scanned for a terms, and those of historical interest are logged. Any input can be printed out or visually displayed on demand, whether it is a logged quantity or not.

The quantities logged include both raw data and values calculated within the computer (such as heat rates, efficiencies etc)

1. Scanning for Alarms: By consolidating all alarm functions in one piece of equipment a comprehensive alarm system is provided. A major advantage of computer alarm scanning is that the alarm limits may be varied as operating conditions change, thus making the alarm function more meaningful. Further complex checking sequences can be included.

2. Performance Calculations: Since the computer can relate data online, in real time, a continuous and upto-date record of performance is immediately available. Typically performance calculations that may be performed by the RW.300 computer are; net amid heat rate; best possible heat rate for instantaneous environment conditions and so on.

3. Control: The computer produces analog and digital output signals suitable for plant control; positioning, opening, and dosing values, adjusting set points, starting and stopping motors etc

Bayo A. (2000) postulates that marketing (Billing unit) of the EEDC should focus on the consumers' needs through research, product development and training. This is a challenge to all in this period of globalization and competition.

The marketing and power monitoring unit of the Enugu distribution company (EEDC) Umuahia branch, which is the case study of this research, comes in direct contact with the teeming population and as such, all possible efforts has to be made in betting the customers satisfied. In the light bills are expected to arrive on schedule computed bill values should not be doctored. Meter reading ought not to be based on mere speculation or estimates. The computerization of these units will seek to eliminate these and other anomalies involved in the billing of customers. In the case of the partial automated meter reading, as it is with the digital meters, the production processed involved in the production of the meter cards should be free from dubious programming. Customers should also be given the proper information on how to use these meters reorientation of the customers.

EEDC as an organization is bound to face some form of risk. It could be in the form of economic risk, market risk, or business risk. Economic risk can arise as a result of uncertainties as regards the economy of the nation. The market risk refer to the risk the company experience owing to failure or impairments of particular financial securities or assets that diminishes the marketing power of the company. When uncertainties are experienced in the investments and financial decision of the corporation, we have business risk. Such form the risks increase the deviation of the actual customers or benefits from the anticipated benefits. Ihesiudo, S (2007) writing on this issue, states that every decision made by individuals or business organizations such as EEDC involves some risks or uncertainty. He added that an event or decision is uncertain when it is subject to unknown factors.

\section{Objectives Of The Study}

This research is carried out in order to identify the problems of the manual or partially computerized system; employed in information technology (IT) potentials on customers' services, staff responsibilities and the organization in general, as well as ascertaining whether the computerized system is of positive impact to the general services structure or a threat to the staff's job security.

It also investigates how the management is able to acquire the relevant hardware and software necessary in running the new system as well as the cost effectiveness of the venture.

Finally, the research will actualized a software engineering solution to the current challenges confronting the nation's power supply system.

\section{System Investigation}

\section{Materials And Methods}

Due to the nature of the topic the following fact finding methods were used:

Structured interviews: This approach was adopted to ensure adequate and consistent response because I took a visit to Enugu Electricity Distribution Company Umuahia, with well-structured and boldly printed questions, accompanied by some of my friends, to seek for option, the survey attempted to capture both quality and quantitative data from staff of the EEDC. This interview covered: 
- $\quad$ The respondents themselves (staff)

- $\quad$ Knowledge of computer usage

We made sure the respondents understood the questions, and they were open and happy to discuss their problems and made suggestion on how it can be solved. This method helped us to have first-hand knowledge about their method of operation and some of the problems they encounter and how this project once implemented will be of great assistant to them.

Questionnaire: A well-structured and simple question was prepared and shared to be learned among them, for other personal information that may not be disclosed in public. Also some worker currently in service was given to seek their option on this. It really helped me and they were pleased that somebody is thinking towards improving their operation.

Others: Data from this project was also sourced from:

- Journals: information for this project was also sourced from related write up and researches carried out by prominent people.

- Internet: I visited the internet for researches on Enugu Electricity Distribution Company.

\section{Problems of the Existing System}

Some problems associated with the existing partially computerized system are as follows:

- Delay of bill dispatching to customers

- $\quad$ Generation of accurate computed bills, is below average.

- $\quad$ Lack of access to meters

- Ineffective power monitoring

- $\quad$ Low level of the security as files are easily misplace or taken away

- Does not enhance profitability and quick decision making.

\section{System Analysis}

Firstly, we can describe system as an inter-related component that joins together to perform a particular task. It also the collection of units, facts and information which are inter-related under one roof to produce a common goals.

In building up a system, there are things that can be considered base on the relevant of the system and he repay from the system include people, components and equipment that process input in a specific way to produce on output.

System analysis is the process of analyzing a system with the potential goal of improving or modifying it. The data was sourced from the branch offices of Enugu Electricity Distribution Company Umuahia.

As much as we want to improve on the current operation of the existing system in the saving account sector, the existing system has its aim and objectives which are:

Reduces stress

Respond to trends faster Improve Customer Service Improve Marketing

Control the money

As far as the existing system is concerned although it has little advantage, it has a big and disastrous problem which its main problem is that the power sector and transactions mostly doesn't match.

\section{Overview Of System Design}

The designing of a new system starts with incorporation of all the data and procedures into functional program design to carry out a computerized power monitoring system in Enugu Electricity Distribution Company using Visual Basic.NET Language to produce the software. Computerized Power monitoring system offers a wide selection of features to improve control of power billing system and to detect power usage in power sector business and save time spent trying to get the actual billing of power in different houses or household and their time of power subscription and their supposed time of expiration and power consumption. With this system, the EEDC operator activates the power consumption card in the system for activation to enable them monitor the use of light and their expiration period. Then the cabling process is being simulated to the software to enable the EEDC monitor the usage of light in the households, for example if a power user bought a power usage card of $30 \mathrm{KW}$ and happens to have $5(60 \mathrm{~W})$ bulbs in his house, it can be done in such a way that he will be exhausting $300 \mathrm{~W}$ per hour in his house and the $30 \mathrm{KW}$ supposed to have been exhausted in 
300 hours. So after 300 hours of keeping the $5(60 \mathrm{~W})$ bulb ON the power usage card will be exhausted.

This chapter which explains the software aspect of the project, we will talk about the language use, data requirements, features of the language and flowchart of the design.

\section{INPUT/FORM DESIGN}

The input processes carried out mostly is the process of feeding in the activation of the power usage card for proper monitoring of power usage card of the subscription details which will be fed into the MySQL database for proper documentation the input/Form Design can be seen from Appendix A (Fig 4.0)

\section{PROCESS DESIGN}

The processing done here is working with the variety of subscription ordered for by the customer with the corresponding amount attached to it, in each subscription there will be a power usage credit limit attached to the subscription and there will also be a time duration in days attached to the subscription, in case the available balance or the time duration or the power usage consumption reaches its the maximum the software detects the power usage subscription as invalid one and terminates the power usage by switching the power from ON to OFF.

This phase of the project shows the procedure used to design the new system, as shown below:

Validate users entry

Asks for the user's Authorization

(Username \& password

Display the main menu

Asks for input of the subscription

Generates a page with the Fraudlent details

Updates the Database with the input

Fig 4.1: Process Design Chart

\section{OUTPUT DESIGN}

The output design can will be viewed from the computer about the subscribers and their usage details comprises of all their subscription details including their power consumption usage and the state of their power usage, which is displayed in Appendix A

\section{DATABASE DESIGN}

MySQL Database Management system is used in the designing of the database used in course of this software (Computerized Power Monitoring System, a Case study of EEDC Umuahia).

Database design is the bone marrow of the software called 'Computerized Power Monitoring System)' because it is the place where all the energy power subscriber's information are being stored for reference purposes about their power consumption/usage by calling upon then time without number to detect any fraud or household power not reading the meter of the subscription plan.

MySQL is an open source relational database management system (RDBMS) that runs as a server providing multi-user access to a number of databases. MySQL ships with no GUI tools to administer MySQL databases or manage data contained within databases. The database design codes and the table structure of the Database are being displayed in Appendix B.

\section{PROGRAM DESIGN}

The new system was design in menu format, as follows:

- Enter the user name and password to check for authorization

- If password is correct the main menu is displayed, if not the system request for the correct user password.

- From the menu display, the user select from FILE

- FILE contain submenu like New, Display, and Exit

- New Form - if selected from the submenu, the INPUT form will be displayed, here the officer fill in the customer's subscription details or will be required to call the submitted information from database if already submitted.

- Display Form: This displays the information and the status of the subscription of the subscriber. This form gives out the information of the subscriber as active or not active and the number of power consumption.

- Prints Form - if selected, it can print the details of the power consumption the subscriber for easy tracking/monitoring and documentation. 
SYSTEM IMPLEMENTATION

The Application "Computerized Power Monitoring System" was designed with VISUAL BASIC PROGRAMMING LANGUAGE (VB.NET); this is because VB is real time, Object Oriented Programming (OOP) language and can work across other platforms of operating systems. The Database is designed in MySQL Database Management System which is a flexible and reliable database package and can also contain large information packaged into it.

\title{
Hardware Requirement
}

For effective use of the new design, the minimum requirements for the hardware components are:

\author{
Components Specifications \\ Processor speed Pentium4 board with 1GHZ speed \\ Ram size $\quad 128 \mathrm{MB}$ \\ Hard Disk 40GB \\ Display Unit 14" Monitor (VGA) \\ Cd Rom Writer X54 \\ Keyboard Window enhance \\ Mouse Optical \\ Printer LaserJet or DeskJet
}

\section{Software Requirement}

The least operating system that must be used is Window XP professional, although window 7 or 8 is better. Also other software like MySQL Server 5.0 upwards or Wamp server which comprises of phpmyadmin for dumping of the SQL file is very essential for the proper running of the application server and Visual Basic.NET Software (Visual Studio 2007, 2010 and 2012 version).

\section{- $\quad$ Program Flow Chart}

Detect Connection of Peripherals/Electric Connections

Send Powerized Signal on power Connection

YES

Required Power Available ?

Acknowledgement Received

Query Peripheral Device for Proper Requirement

YES

NO

$\mathrm{NO}$

NO

Detect Peripheral of the Available Power Voltage Wattage Adjust Power Supply in accordance with standard

Available Power Acceptable

YES

Adjust Power Supply deliver required power Deliver Available Power

Deliver Standby Power

YES

Real Time Monitor and charge ON?

NO

\section{System Documentation}

This phase of the project talks about how the system works, because the system is menu driven, all that is required are:

Stage 1: Splash page

Once the program is loaded, the welcome page is displayed, after few seconds (say 10sec)

Stage 2; Authorization Page

This stage displays the authorization form where user will enter his/her username and password, then the system authenticate the pass word before moving to the next stage

Stage 3: Main menu page

This phase contains menu like FILE, DISPLAY AND PRINT, the File menu contains sub menu like New Subscription record and Exit, the Display Menu contain submenu like: Display All Record and the subscription 
details and Print Menu contain submenu like: Print All, Print One etc.

\section{Project Costing}

Due to the lack of some of the knowledge needed to know what exactly is needed in power sectors like Enugu Electricity Distribution Company (EEDC) and the way rate of their power consumption are being carried out in the power sector in Nigeria, I tried as much as possible to carry out some research about power consumption in Nigeria power sector like the one in Enugu Electricity Distribution Company in Umuahia which is the one I used as my case study and the way the staff operates before I could be able to start developing this software "Computerized Power Monitoring system".

Actually, where costing comes into the project is basically in the research process and the stress in putting the codes together in other to make the software quite efficient.

But the Actual cost for the Software for Commercial purpose of the Enugu Electricity Distribution Company in Umuahia in monitoring the power usage by users in a computerized manner for its professional efficiency is $\mathrm{N} 100,000$.

\section{Results, Recommendation And Conclusion}

Based on this exploratory study, it appears that the introduction of computerized power monitoring system may result in a workplace that is less satisfying to many employees. Among the possible contributing factors are the increases in stress in Enugu Electricity Distribution Company in Umuahia organizational control of power. This Computerized power monitoring system happens to be very efficient in the monitoring of power usage and billing because it has been a hard nut to crack to satisfy customer with manual billing and meter reading process because majority of the customers doubt the manual process of EEDC billing for their light usage, but this computerized monitoring system goes a long way to minimize the power usage drastically to make the customers have so much believe in EEDC billing process because they will surely believe that their power usage will now be Pay as you use process not estimated power usage billing.

\section{Recommendation}

Although this software happens to be developed as a case study of Enugu Electricity Distribution Company (EEDC) Umuahia but it needs to be implemented in such a way that it will be as a web based program that will cut across the whole Nigeria branches of EEDC so that the information of each household and their metering system and reading will have different database in various locations of EEDC but will have the same server so that monitoring of the whole power system can be of high efficiency. Although high simulation of this project is not done physically due to lack of equipment required in simulating the software direct to the metering system but for efficiency and the commercial use of the software, proper simulation to the metering system is to be done for the enhancement of the software usage.

\section{Conclusion}

In conclusion, computerized power monitoring system may provide an increase in the amount of quantitative feedback available to all levels of the Power sector. This quantitative information may underlie the general perception that these systems increase the fairness of the performance evaluation system and increase the Power sector's ability to judge performances, it seems that increasing the quantitative information available to management tends to minimize the emphasis given to the subjective information in performance evaluation in the Power sector.

[1]. Ayankola, $\mathrm{M}$ and Ezeobi O. (2010) Why States may invest in Electricity Distribution (online) available Http:nigerianbestforum.com/generaltopics

[2]. Ayodele, A.S. (2008) Improving and Sustaining Power (electricity) supply for socio Economic Development in Nigeria (online) Available Http:nigerianbestforum.com/general topics

[3]. Bayo,A. (2000) Marketing NEPA Resources. Ibadan: Bi Monthly Magazines.

[4]. Christer, I. (2007) Power monitoring Systems (online) available http:nigerianbestforum.com/general topics.

[5]. Ihesiudo, S.O (2007): The Principal of Business financing Chedal Global Press Aba

[6]. Issues and Options Department of Economics University of Ibadan, Ibadan Nigeria.

[7]. Jacobson R.E (2010) The RW-300 Control and Monitoring System. The Thompson Ranowooldridge products company, Beverly Halls Califfornia

[8]. Wikipedia (2011) power Holding Company of Nigeria (online) available: http//en.wikipedia.org/;wiki/power-holding-company-ofnigeria.

[9]. Wikipedia (2013) Enugu Electricity Distribution Company of Nigeria (online) available: http//en.wikipedia.org/;wiki/Enugu Electricity Distribution - company-of-Nigeria. 


\section{APPENDIX}

INTERFACE
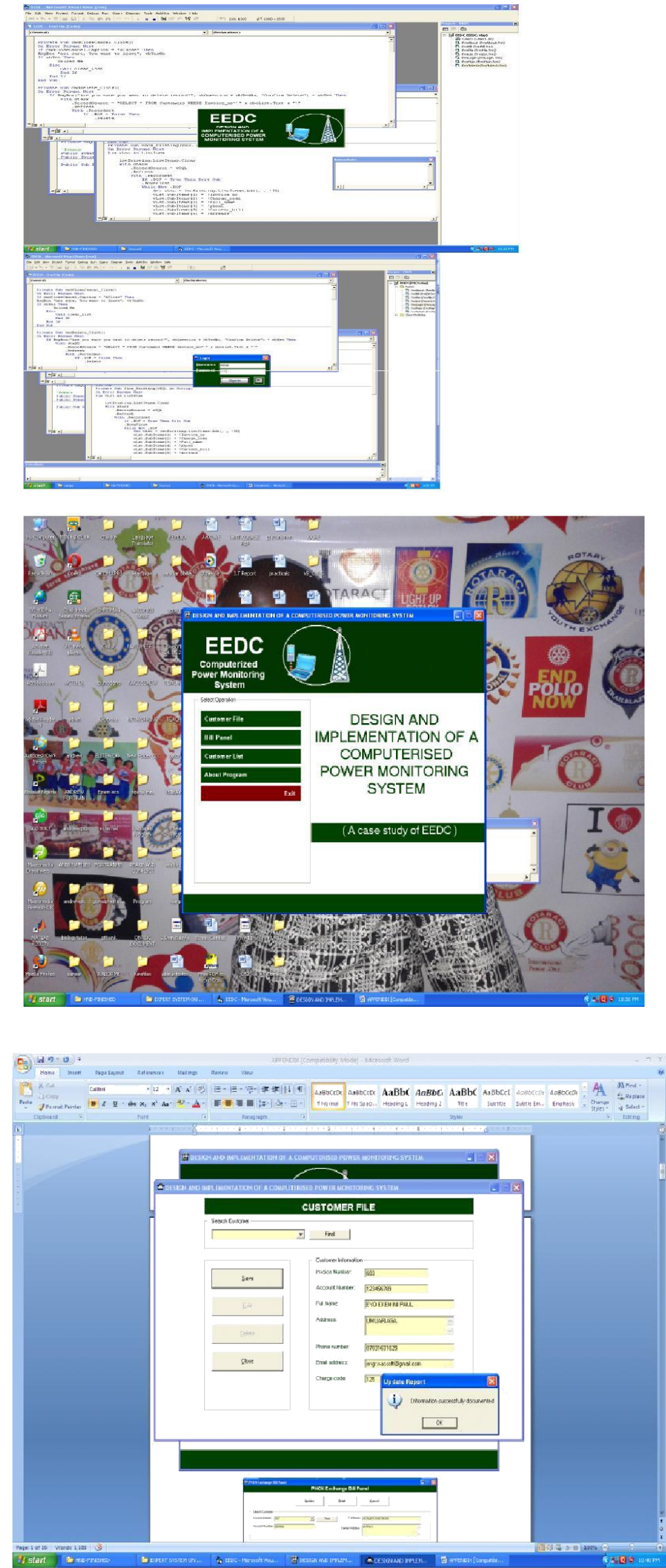

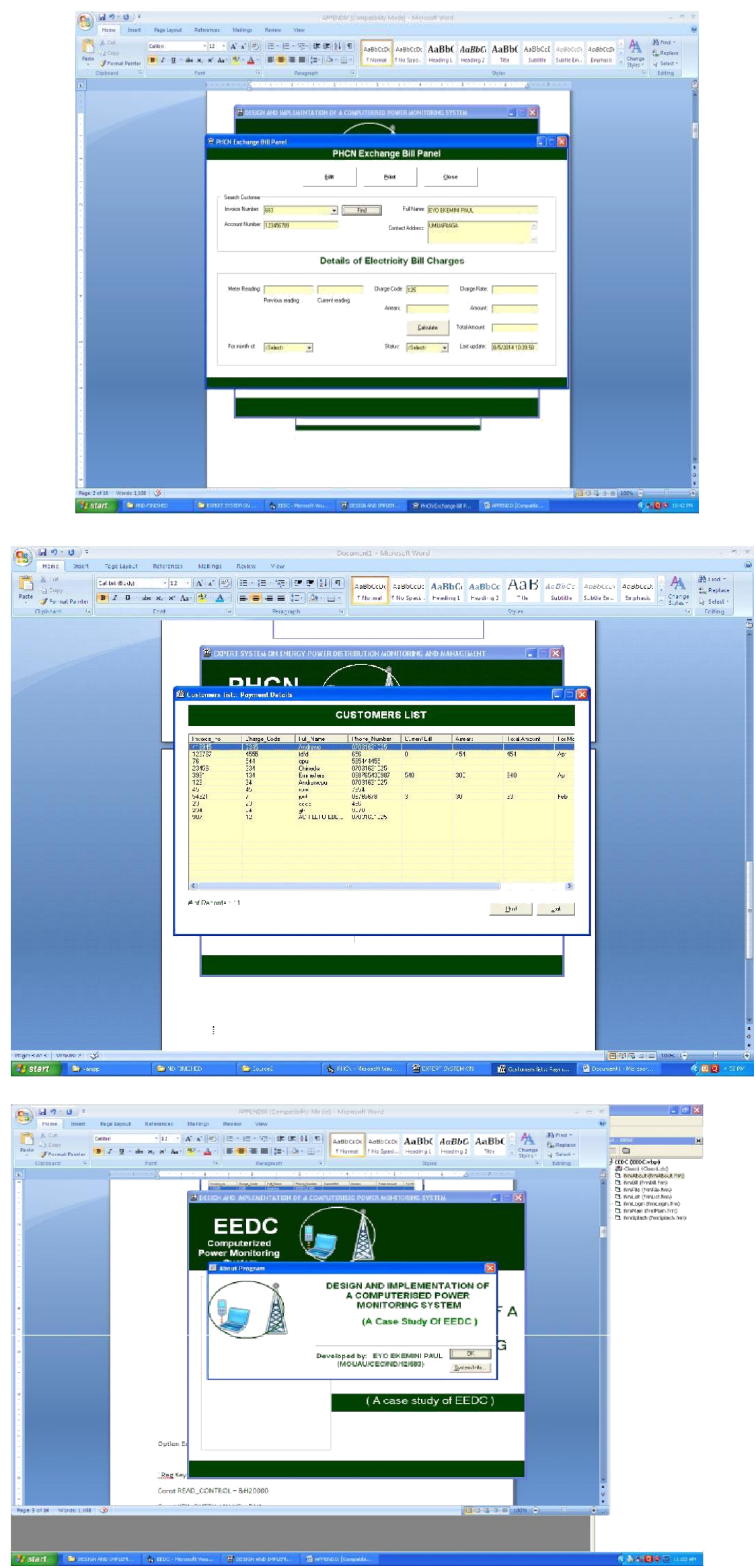


\section{SOURCE CODE}

Option Explicit

' Reg Key Security Options...

Const READ_CONTROL $=\& \mathrm{H} 20000$

Const KEY_QUERY_VALUE $=\& \mathrm{H} 1$

Const KEY_SET_VALUE $=\& \mathrm{H} 2$

Const KEY_CREATE_SUB_KEY $=\& H 4$

Const KEY_ENUMERATE_SUB_KEYS $=\&$ H8

Const KEY_NOTIFY $=\& \mathrm{H} 10$

Const KEY_CREATE_LINK $=\& \mathrm{H} 20$

Const KEY_ALL_ACCESS $=$ KEY_QUERY_VALUE + KEY_SET_VALUE + _ KEY_CREATE_SUB_KEY

+ KEY_ENUMERATE_SUB_KEYS + _KEY_NOTIFY + KEY_CREATE_LINK + READ_CONTROL

' Reg Key ROOT Types...

Const HKEY_LOCAL_MACHINE $=\&$ H80000002

Const ERROR_SUCCESS $=0$

Const REG_SZ $=1 \quad$ ' Unicode nul terminated string

Const REG_DWORD $=4$ ' 32-bit number

Const gREGKEYSYSINFOLOC $=$ "SOFTWAREIMicrosoft Shared Tools Location"

Const gREGVALSYSINFOLOC $=$ "MSINFO"

Const gREGKEYSYSINFO = "SOFTWAREIMicrosoftlShared ToolsıMSINFO"

Const gREGVALSYSINFO = "PATH" 